\title{
Analysis of Processing Parameters to Avoid Additional Oxygen Contamination During Production of Zr-based Bulk Metallic Glasses by Suction Casting in an Arc-melting Furnace
}

\author{
Nelson Delfino de Campos Neto ${ }^{a, b^{*}}\left(\mathbb{1}\right.$, , Flavio Soares Pereira ${ }^{a}$, Marcelo Falcão de Oliveira ${ }^{a}$
}

\author{
${ }^{a}$ Universidade de São Paulo, Escola de Engenharia de São Carlos, Departamento de Engenharia de \\ Materiais, Avenida João Dagnone, 1100, CEP 13563-120, São Carlos, SP, Brasil. \\ ${ }^{b}$ Colorado School of Mines, George S. Ansell Department of Metallurgical and Materials Engineering, \\ 1500 Illinois St., Golden, CO, 80401, USA.
}

Received: June 24, 2020; Revised: August 18, 2020; Accepted: November 21, 2020

\begin{abstract}
This study first reports details of a successful arc-melting furnace in the production of bulk metallic glasses (BMGs). Also, the study presents the results of a statistical experiment evaluating critical processing parameters that can increase oxygen concentration and its effects on the glass forming ability (GFA) of two $\mathrm{Zr}$-based BMGs. The experiments on $\mathrm{Zr}_{48} \mathrm{Cu}_{46.5} \mathrm{Al}_{4} \mathrm{Nb}_{1.5}$ BMG composite found that using low arc-current $(200 \mathrm{~A})$, short melting time (11 s), positive pressure of argon inert gas trapped in the synthesis chamber, and the absence of prior melting of a Ti-getter results in a lower oxygen contamination in the produced alloy. The second experiment using the Vitreloy 105 BMG alloy proved the previous findings.
\end{abstract}

Keywords: Bulk metallic glasses, Glass forming ability, Arc-melting; Suction casting, Ti-getter.

\section{Introduction}

Most work related to the synthesis of BMGs focuses on variables aiming to improve the GFA of those alloys, i.e., the base composition ${ }^{1}$, the influence of microalloying ${ }^{2}$ and the deleterious effect of contaminations as oxygen on $\mathrm{Zr}$ based $\mathrm{BMGs}^{3}$. Though necessary, these variables are not enough to achieve the amorphous structure on BMGs, and process variables have a great influence on the structure formation as well. The production of BMGs started with techniques for rapid solidification processing ${ }^{4}$, and the alloys have been developed during the years in such a way that the dependency of higher cooling rates has decreased considerably, i.e. $10^{2}-10^{3} \mathrm{Ks}^{-1}$ in Pd- and Pt-based systems ${ }^{5}$. One of the most consolidated methods to manufacture BMGs is the copper mold casting with great attention to suction casting $^{6}$ and tilting casting ${ }^{7}$.

The set-ups used in BMGs production commonly are the following8: fast and powerful heat source, evacuation and back filling the chamber with inert gas, use of melting oxygen Ti-getters inside the chamber, and remelting and flipping of the ingot to ensure homogeneity. Although these set-ups successfully produce BMGs, the literature lacks in a consistent investigation of the production variables in the final product.

The objective of this study is to present some details of our arc-melting furnace that have been successfully producing BMGs over the years together with a couple of statistical experiments performed to evaluate four process variables that may act directly on the final oxygen content of the produced BMGs.

*email: nelsondden@gmail.com

\section{Materials and Methods}

Figure 1a shows a picture and Figure $1 \mathrm{~b}$ shows a drawing of the several components that integrate the arc-melting furnace. The main components are the fusion chamber, the vacuum system, the arc-melting electrode, the power supply, copper base, mold assembly, and the inert gas inlet system.

The fusion chamber is made of $304 \mathrm{~L}$ stainless steel. The chamber walls have four viewports, 90 degrees from each other, made of sodium borate glass, where three of them are used to view the samples and one is used as light source. A copper coiled tube soldered to the external surface of the vessel acts as a cooling system. Room temperature water flows through the coil, the arc-melting electrode, the copper hearth and in the mold.

The main component of the vacuum system is an Edwards RV12 dual stage rotary vane vacuum pump that acts through the entire system. Under the copper mold, there is a pre-vacuum chamber that creates the differential pressure necessary for the suction process. Two manual valves separate the vacuum pump from the fusion chamber as well as the copper mold from the pre-vacuum chamber. The pre-vacuum chamber is continuously degassed by the vacuum pump. All connections are standard vacuum connections type NW16 and NW25 with the flanges sealed by nitrile O-rings.

Two concentric tubes and a cylindrical bar compose the arc-melting electrode, as shown in Figure 2a. The external tube is made of 304L stainless steel and the inert gas is injected into the chamber through an annular space between its inside surface and the mild tube. The mild tube and the cylindrical bar are made of electrolytic copper. They are attached to the power supply, and room temperature water flows through the annular space. The electrode tip is made of a thoriated tungsten standard alloy used for the TIG welding process. 

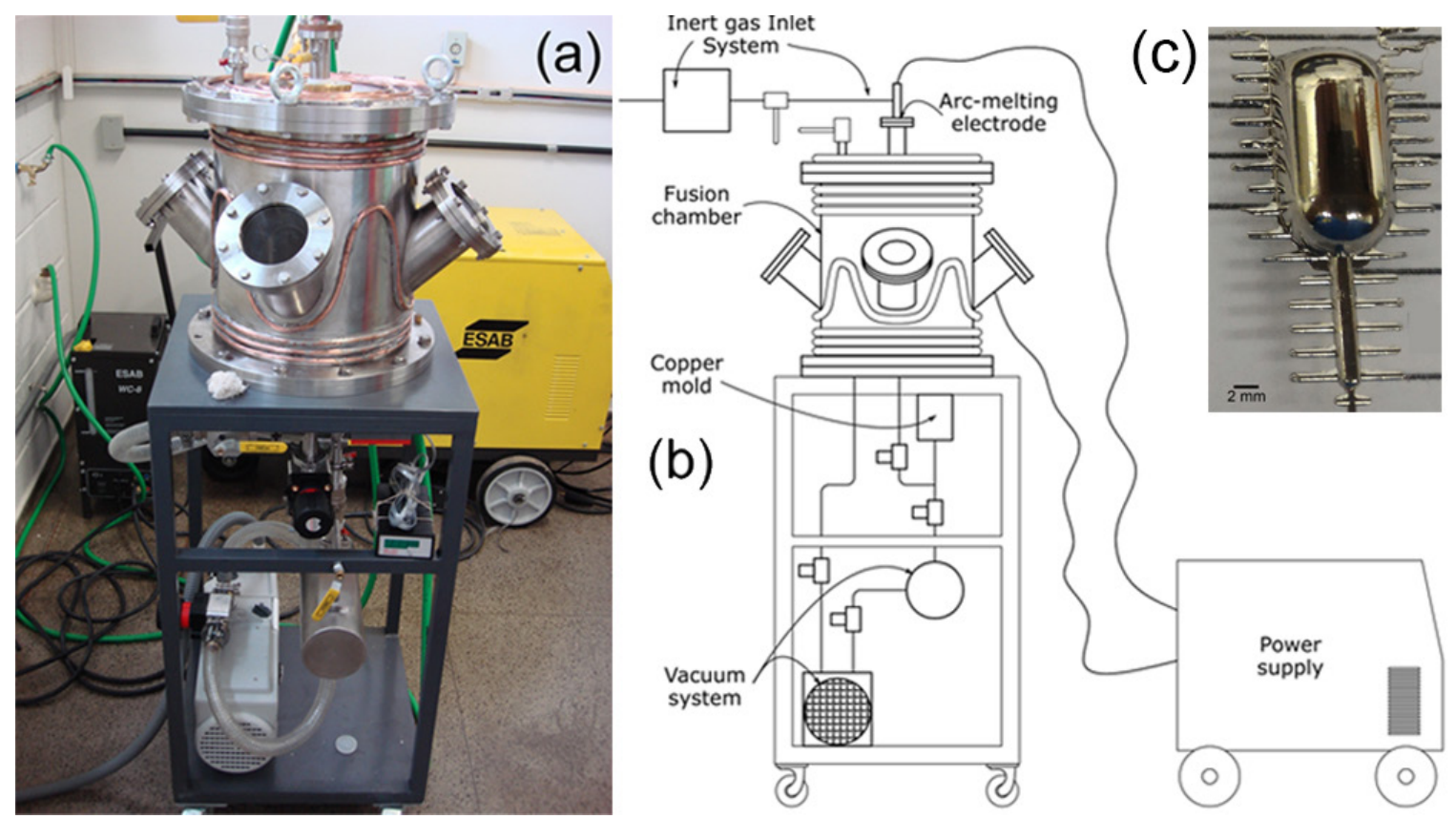

Figure 1: Arc-melting furnace (a) picture of the equipment, (b) drawing, and (c) example of one of the produced samples.
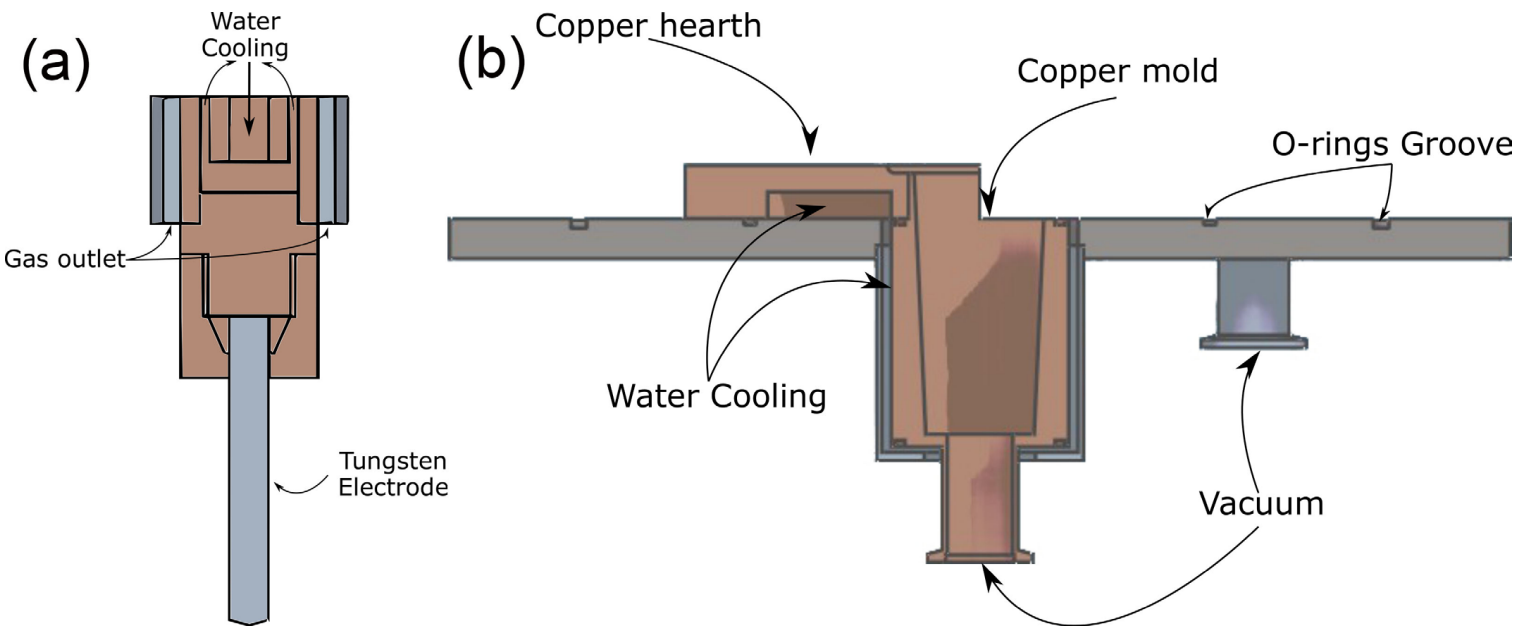

Figure 2: Detailed drawing of (a) arc-melting electrode and (b) furnace base, copper base and conical assembly for the mold.

The power to generate the electric arc is provided by a welding rectifier (ESAB 400A). It can be operated from $200 \mathrm{~A}$ to $400 \mathrm{~A}$, under direct current, with a nominal apparent power of $14.5 \mathrm{kVA}$. The negative pole is connected to the arc-melting electrode, and the grounding cable is connected to the fusion chamber. A PTFE sphere connected to the external tube of the arc-melting electrode prevents the system from short circuiting.

The furnace's hearth is made of electrolytic oxygen free copper, in order to achieve higher heat transfer during the sample's melting process. It is provided with a conical assembly, where the copper mold is placed as shown in Figure $2 \mathrm{~b}$. It has a copper crucible where the ingot is placed to be molten and suctioned inside the mold by opening a manually operated valve connected to the vacuum booster vessel to quickly fill the mold.

The inert gas inlet system is settled to use argon, but other inert gases are suitable with easy, such as helium or a mixture of gases. Argon 5.0 PA quality is used in the system. The line is connected to a LiH based (Supelco OMI-2 INDICATOR TUBE) solid state polishing purifier which removes many contaminants, such as water and oxygen, delivering in the furnace chamber a higher purity argon gas. This is especially oxygen free (less than $10 \mathrm{ppb}$ ).

Two Zr-based BMGs alloys were selected to perform this study. The first alloy with composition $\mathrm{Zr}_{48} \mathrm{Cu}_{46.5} \mathrm{Al}_{4} \mathrm{Nb}_{1.5}$ (at.\%) is a $\mathrm{BMG}$ composite with excellent mechanical properties due to the combination of B2 particles embedded in the amorphous matrix ${ }^{9}$. The glass forming ability (GFA) of this first 
alloy is decreased by the increasing in oxygen concentration leading to the formation of brittle phase ${ }^{10}$. The second alloy is commercially known as Vitreloy 105 with composition $\mathrm{Zr}_{52.5} \mathrm{Cu}_{17.9} \mathrm{Ni}_{14.6} \mathrm{Al}_{10} \mathrm{Ti}_{5}$ (at.\%). The Vitreloy 105 has been reported to be very sensitive to oxygen contamination ${ }^{11}$, when even in a small wppm increase in the oxygen concentration in the alloy can lead to a decrease in the critical amorphous sample size from $10 \mathrm{~mm}$ to $4 \mathrm{~mm}^{3}$. The $\mathrm{Zr}_{48} \mathrm{Cu}_{46.5} \mathrm{Al}_{4} \mathrm{Nb}_{1.5}$ alloy was produced from high purity raw materials in 2 master ingots with approximately $100 \mathrm{~g}$, using $350 \mathrm{~A}$ and $22 \mathrm{~s}$ melting time as melting parameters, being flipped and remelted at least 5 times to ensure composition homogeneity. The $100 \mathrm{~g}$ master ingots were cut by a wired electric discharge machine, which resulted in 8 pieces with approximately $10 \mathrm{~g}$ each. Vitreloy 105 master alloy was purchased from Materion in 3/4" rod bar with $400 \mathrm{~mm}$ length and nominal oxygen concentration 180 wppm. The bar was sectioned with a diamond disc in pieces with approximately $10 \mathrm{~g}$.

The system was evacuated down to $10^{-4} \mathrm{kPa}$ followed by back filling with argon until internal pressure reached $170 \mathrm{kPa}$, repeating this procedure three times, leaving the system pressurized in the last stage, to minimize possible atmospheric contamination due to leakage from outside. Table 1 shows the final melting step used in each one of the $10 \mathrm{~g}$ sectioned ingots following the parameters. The samples were suction cast into a water-cooled copper mold, producing stepped samples that were 2 and $10 \mathrm{~mm}$ in diameter. Figure $1 \mathrm{c}$ shows one of them.

Seven factors that could be source of additional oxygen contamination on the final produced alloy were identified: electric arc current, gas flow, melting time, use of Ti-getter, the system evacuation, chamber pressure, and gas purity. An experiment to account for two levels and eight factors, $2^{8}$, would require 256 samples with no replications. It was chosen to study the first 4 factors considered the most important ones, keeping fixed all other factors to avoid bias. Other possible extra sources of oxygen contamination can be identified such as cleaning of furnace and alloy elements, preparation and handling of the sample. To avoid bias, these extra sources were kept fixed and even for all samples.

The electric arc current is directly related to the energy transferred from the electric arc to the samples. As a result, the alloys' temperature increases and so does its capacity for absorbing oxygen from the chamber. The two levels for this factor were defined by the maximum continuous capacity of our power source, $350 \mathrm{~A}$, higher level, and the least necessary current to melt the samples, $200 \mathrm{~A}$, at a lower level. In even lower currents, the electric arc was not stable or had no capacity to melt the whole sample.

As described before, the oxygen contamination is present inside the fusion chamber. Its source can be related to the presence of oxygen in the chamber atmosphere, due to leakage, the impurity of the inert gas, or degassing from the chamber's walls and copper hearth. The gas flow factor is based on the hypothesis that the continuous renewal of the environment gas will expel the oxygen from the chamber once it is less dense than the argon. The higher level is defined as the constant renewal of gas and the lower level as the static atmosphere.

The melting time is related to the $\mathrm{Zr}$ ability to getter oxygen. Once the alloy is melted, the $\mathrm{Zr}$ is activated and starts to associate with the oxygen. The longer the time as a melt, the higher the amount of oxygen content, until the solubility limit of the alloy. Melt time can also be used to allow some oxides to dissolve and dissociate, leaving the alloy free of oxygen. The higher level, $22 \mathrm{~s}$, was defined as the maximum time, in a $350 \mathrm{~A}$ current, that the alloy could be submitted. Longer times could damage the copper hearth. The lower limit, $11 \mathrm{~s}$, was defined as the minimum time, in a 200 A current, to completely melt the samples. Lower times would result in partial melting.

It is common in the literature to describe the use of Ti-getter to remove the remaining oxygen from the chamber atmosphere. We defined the lower level as the absence of Ti-getter melting prior the fusion of the sample. The higher

Table 1: Variables and oxygen responses of the $\mathrm{Zr}_{48} \mathrm{Cu}_{46.5} \mathrm{Al}_{4} \mathrm{Nb}_{1.5}$ and Vitreloy 105 experiments.

\begin{tabular}{|c|c|c|c|c|c|c|c|c|c|c|c|}
\hline \multicolumn{7}{|c|}{$\mathrm{Zr}_{48} \mathrm{Cu}_{46.5} \mathrm{Al}_{4} \mathrm{Nb}_{1.5}$ experiment } & \multicolumn{5}{|c|}{ Vitreloy 105 experiment } \\
\hline \multirow[b]{2}{*}{ Run \# } & \multirow[b]{2}{*}{ Block } & \multicolumn{4}{|c|}{ Variables } & \multirow{2}{*}{$\begin{array}{c}\text { Response } \\
\text { Oxygen } \\
\text { (wppm) }\end{array}$} & \multirow[b]{2}{*}{ Run \# } & \multirow[b]{2}{*}{ Block } & \multicolumn{2}{|c|}{ Variable } & \multirow{2}{*}{$\begin{array}{c}\text { Response } \\
\text { Oxygen } \\
\text { (wppm) }\end{array}$} \\
\hline & & $\begin{array}{c}\text { Eletric arc } \\
\text { current }\end{array}$ & Gas flow & $\begin{array}{l}\text { Melting } \\
\text { time }\end{array}$ & Ti-getter & & & & $\begin{array}{c}\text { Eletric arc } \\
\text { current }\end{array}$ & $\begin{array}{c}\text { Melting } \\
\text { time }\end{array}$ & \\
\hline 1 & 1 & $200 \mathrm{~A}$ & Static & $11 \mathrm{~s}$ & No & $281 \pm 47$ & 1 & 1 & $350 \mathrm{~A}$ & $22 \mathrm{~s}$ & $195 \pm 24$ \\
\hline 2 & 1 & $350 \mathrm{~A}$ & Static & $11 \mathrm{~s}$ & Yes & $458 \pm 85$ & 2 & 1 & $200 \mathrm{~A}$ & $11 \mathrm{~s}$ & $148 \pm 22$ \\
\hline 3 & 1 & $200 \mathrm{~A}$ & Dynamic & $11 \mathrm{~s}$ & Yes & $299 \pm 30$ & 3 & 1 & $350 \mathrm{~A}$ & $11 \mathrm{~s}$ & $171 \pm 11$ \\
\hline 4 & 1 & $350 \mathrm{~A}$ & Dynamic & $11 \mathrm{~s}$ & No & $304 \pm 58$ & 4 & 1 & $200 \mathrm{~A}$ & $22 \mathrm{~s}$ & $187 \pm 53$ \\
\hline 5 & 1 & $200 \mathrm{~A}$ & Static & $22 \mathrm{~s}$ & Yes & $293 \pm 58$ & 5 & 1 & $200 \mathrm{~A}$ & $11 \mathrm{~s}$ & $161 \pm 25$ \\
\hline 6 & 1 & $350 \mathrm{~A}$ & Static & $22 \mathrm{~s}$ & No & $258 \pm 50$ & 6 & 1 & $200 \mathrm{~A}$ & $22 \mathrm{~s}$ & $190 \pm 49$ \\
\hline 7 & 1 & $200 \mathrm{~A}$ & Dynamic & $22 \mathrm{~s}$ & No & $370 \pm 11$ & 7 & 1 & $350 \mathrm{~A}$ & $11 \mathrm{~s}$ & $188 \pm 42$ \\
\hline 8 & 1 & $350 \mathrm{~A}$ & Dynamic & $22 \mathrm{~s}$ & Yes & $307 \pm 85$ & 8 & 1 & $350 \mathrm{~A}$ & $22 \mathrm{~s}$ & $213 \pm 38$ \\
\hline 9 & 2 & $200 \mathrm{~A}$ & Static & $11 \mathrm{~s}$ & No & $217 \pm 70$ & & & & & \\
\hline 10 & 2 & $350 \mathrm{~A}$ & Static & $11 \mathrm{~s}$ & Yes & $333 \pm 81$ & & & & & \\
\hline 11 & 2 & $200 \mathrm{~A}$ & Dynamic & $11 \mathrm{~s}$ & Yes & $256 \pm 58$ & & & & & \\
\hline 12 & 2 & $350 \mathrm{~A}$ & Dynamic & $11 \mathrm{~s}$ & No & $388 \pm 89$ & & & & & \\
\hline 13 & 2 & $200 \mathrm{~A}$ & Static & $22 \mathrm{~s}$ & Yes & $332 \pm 125$ & & & & & \\
\hline 14 & 2 & $350 \mathrm{~A}$ & Static & $22 \mathrm{~s}$ & No & $322 \pm 84$ & & & & & \\
\hline 15 & 2 & $200 \mathrm{~A}$ & Dynamic & $22 \mathrm{~s}$ & No & $248 \pm 10$ & & & & & \\
\hline 16 & 2 & $350 \mathrm{~A}$ & Dynamic & $22 \mathrm{~s}$ & Yes & $434 \pm 100$ & & & & & \\
\hline
\end{tabular}


level was the activation (melting) of $10 \mathrm{~g}$ of a pure Ti piece by 10 seconds prior the melting of the alloy.

The first experiment with $\mathrm{Zr}_{48} \mathrm{Cu}_{46.5} \mathrm{Al}_{4} \mathrm{Nb}_{1.5}$ alloy was set to a $2^{4-1}$ experiment with 4 factors and 2 levels (resolution IV $^{12}$ ), as shown in Table 2. With two replicates, the experiment resulted in a total of 16 runs, as shown in Table 1.

The second experiment with Vitreloy 105 was planned and executed after the analysis of results of the first experiment. The justification for this approach is later presented in the results and discussions section. The Vitreloy 105 was a $2^{2}$ experiment, with 2 factors, 2 levels, and 2 replicates. The factors are shown in Table 2, and the results in Table 1.

Oxygen concentration was measured in a Leco RO400 by the inert gas fusion principle using a free oxygen $\mathrm{Ni}$ basket inside a graphite crucible to release the oxygen from the samples according to ASTM-E1019. Three pieces were measured with a mass around $100 \mathrm{mg}$ each for all sectioned $10 \mathrm{~g}$ initial ingots and the same for all final samples produced after the suction casting.

The data collected for both experiments were analyzed using Minitab ${ }^{\circledR}$ software (Version 17). Analysis of variance (ANOVA) was used to determine the significance of the model and factors. The model adequacy was based on the residual analysis where it was checked, whether the errors were normally distributed, the absence of a pattern of the errors and the predicted response, as well as the errors independency. The null hypothesis $\mathrm{H}_{0}$ is rejected for any $p$-value lower than a level of significance $(\alpha)$ of 0.05 . The power curves were calculated fixing an $\alpha=0.05$, the sample sizes for each experiment were plotted against the effect and identified powers of 0.75 , $0.80,0.90$ and 0.95 .

\section{Results and Discussion}

The oxygen response for the initial $\mathrm{Zr}_{48} \mathrm{Cu}_{46.5} \mathrm{Al}_{4} \mathrm{Nb}_{1.5}$ ingots was $217 \pm 22$ wppm, and Table 1 shows the oxygen results for the experiment. The results show that the expanded uncertainty has no distinct pattern. The oxygen analyzer in this range of oxygen concentration has an uncertainty around $10 \mathrm{wppm}$; the remaining uncertainty is due to sample variation. Table 3 shows the ANOVA results.

No significant effect was found, and this might indicate that none of the set-ups produced an oxygen response in the samples. The residual analysis showed a random pattern and a normality test with a p-value of 0.163 , validating the ANOVA. The standard deviation was about $68 \mathrm{wppm}$. Figure 3 a shows the power curve. A power $(1-\beta)=0.80$ observed differences of 100 or more wppm of oxygen in the samples.

The lack of significant factors might be explained by the number of replicates. The power curve in Figure 3 a shows that for the same power value, the increase of replicates can improve the ability to detect differences in oxygen content. The dispersion in the oxygen measurements can be explained by the difficulty in producing the oxygen measurements in BMGs based on high melting temperature and refractory metals.

In order to minimize the problems observed in the first experiment, it was decided to remove two factors, the gas flow and the Ti-getter, as they have shown no significant effect. This decision was based on the main effects plot, Figure $4 \mathrm{a}$, for $\mathrm{Zr}_{48} \mathrm{Cu}_{46.5} \mathrm{Al}_{4} \mathrm{Nb}_{1.5}$ experiment, where closed glass flow and no use of Ti-getter lead to smaller oxygen contents. Figure $4 \mathrm{~b}$ presents the two-way interaction plots to understand which variables are causing an effect in each other for $\mathrm{Zr}_{48} \mathrm{Cu}_{46.5} \mathrm{Al}_{4} \mathrm{Nb}_{1.5}$ experiment. One easy way to

Table 2: Factors, levels and effects of the $\mathrm{Zr}_{48} \mathrm{Cu}_{46.5} \mathrm{Al}_{4} \mathrm{Nb}_{1.5}$ experiment. Vitreloy 105 experiment studied two factors: electric arc current and melting time.

\begin{tabular}{llcc}
\hline \multicolumn{1}{c}{ Factor } & \multicolumn{1}{c}{ Effect } & -1 (low level) & +1 (high level) \\
\hline Arc current & Higher or lower melting temperature & $200 \mathrm{~A}$ & $350 \mathrm{~A}$ \\
\hline Gas flow & $\begin{array}{l}\text { Static or dynamic furnace's atmosphere in a } \\
170 \mathrm{kPa} \text { absolute pressure }\end{array}$ & Static argon in the chamber & $\begin{array}{c}\text { Dynamic argon expelled from } \\
\text { the chamber (30 1/min) }\end{array}$ \\
\hline Melting time & Dissolution of solids in molten alloys & $11 \mathrm{~s}$ & $22 \mathrm{~s}$ \\
\hline Ti-getter & $\begin{array}{l}\text { Remove the remaining oxygen in the furnace's } \\
\text { atmosphere }\end{array}$ & No use of a Ti-getter & $\begin{array}{c}\text { Ti-getter (10 g) melted prior to } \\
\text { the alloy melting by } 10 \mathrm{~s}\end{array}$ \\
\hline
\end{tabular}

Table 3: ANOVA results of $\mathrm{Zr}_{48} \mathrm{Cu}_{46.5} \mathrm{Al}_{4} \mathrm{Nb}_{1.5}$ experiment.

\begin{tabular}{|c|c|c|c|c|c|}
\hline Source & DF & $\mathrm{SS}$ & MS & F-Value & P-Value \\
\hline Model & 8 & 33690 & 4211 & 0.9 & 0.56 \\
\hline Block & 1 & 96.7 & 96.7 & 0.02 & 0.89 \\
\hline Linear & 4 & 23439 & 5860 & 1.26 & 0.37 \\
\hline Electric arc current & 1 & 16129 & 16129 & 3.46 & 0.105 \\
\hline Gas flow & 1 & 729 & 729 & 0.16 & 0.704 \\
\hline Melting time & 1 & 46.7 & 46.7 & 0.01 & 0.923 \\
\hline Ti-getter & 1 & 6534 & 6534 & 1.4 & 0.275 \\
\hline 2-way interactions & 3 & 10155 & 3385 & 0.73 & 0.568 \\
\hline Electric arc current $*$ Gas flow & 1 & 10 & 10 & 0 & 0.964 \\
\hline Electric arc current $*$ Melting time & 1 & 7744 & 7744 & 1.66 & 0.238 \\
\hline Electric arc current $*$ Ti-Getter & 1 & 2401 & 2401 & 0.51 & 0.496 \\
\hline Error & 7 & 32636 & 4662 & & \\
\hline Total & 15 & 66326 & & & \\
\hline
\end{tabular}



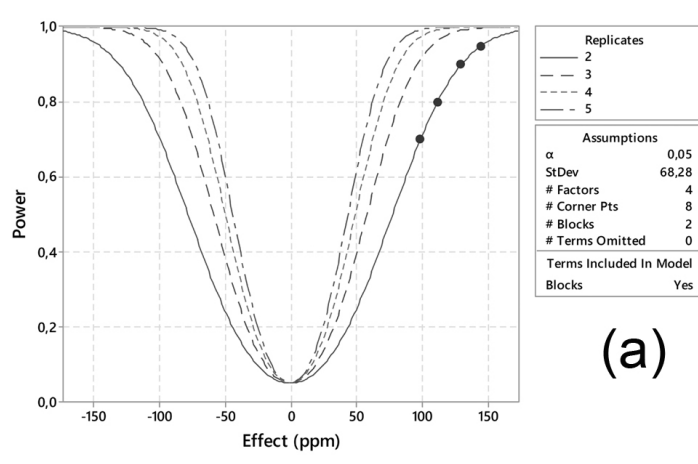

(a)

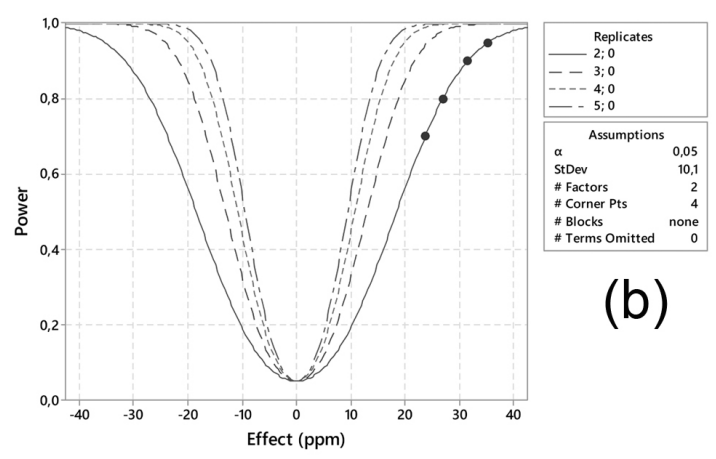

Figure 3: The power curve of the experiments for (a) $\mathrm{Zr}_{48} \mathrm{Cu}_{46.5} \mathrm{Al}_{4} \mathrm{Nb}_{1.5}$ and (b) Vitreloy 105. interpret the two-way interaction plot is to keep in mind that no interactions are shown as parallel lines, and interactions are shown as crossed lines. Therefore, it is possible to identify that the arc current and melting time has the greatest interaction among all studied variables, supporting the decision made.

The second experiment was fixed with a static atmosphere and no use of Ti-getter. Any possible doubt about sample homogeneity was removed from this experiment, since Vitreloy 105 was supplied from Materion. This ensures chemical homogeneity (certificate of chemical analysis provided by Materion). The oxygen response for the second experiment is shown in Table 1 and the ANOVA in Table 4. This experiment showed a significant effect for both factors. This indicates that the set-ups produced an oxygen response. The residual analysis showed a random pattern and a normality test with p-value of 0.409 , validating the ANOVA. The standard deviation was about $10 \mathrm{wppm}$. Figure $3 \mathrm{~b}$ shows the power curve. With a power $(1-\beta)=0.80$, one observed difference higher than 25 wppm of oxygen. The reduction of the number of factors has improved the capacity to observe different responses in oxygen concentration.

The second experiment has shown an improved resolution compared to the first one, and the differences in the oxygen content were about $30 \mathrm{wppm}$ from the lower to the higher level, regardless of the factor, arc current or melting time. It was possible to exclude the hypothesis that the samples started with a saturated oxygen level because the literature

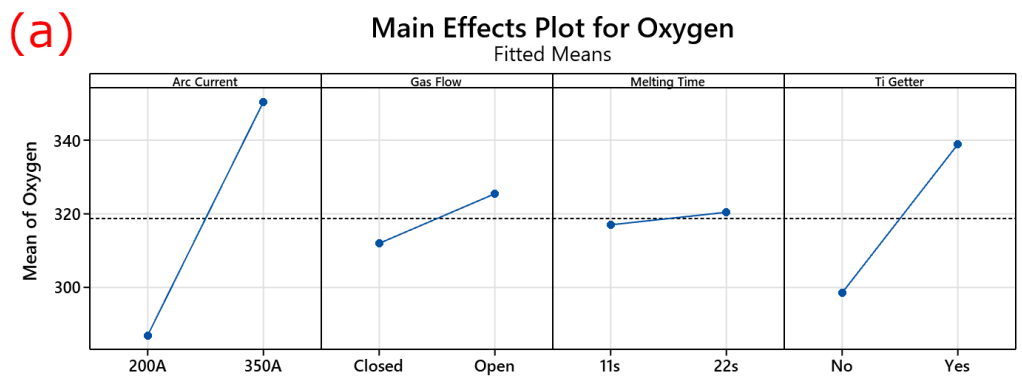

(b)

Interaction Plot for Oxygen

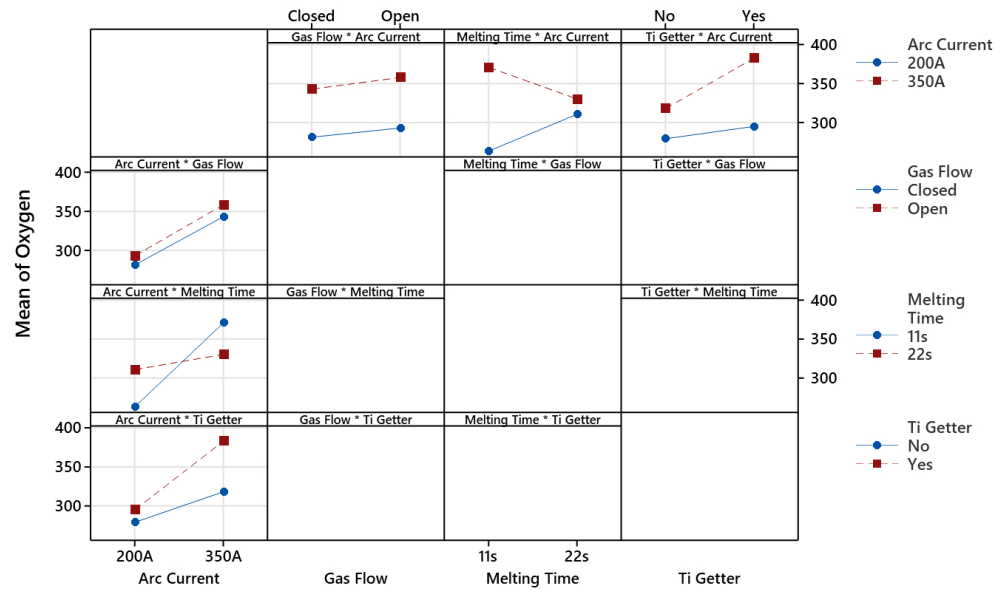

Figure 4: $\mathrm{Zr}_{48} \mathrm{Cu}_{46.5} \mathrm{Al}_{4} \mathrm{Nb}_{1.5}$ experiment plots for (a) main effects and (b) two-way interactions. 
Table 4: ANOVA results of Vitreloy 105 experiment.

\begin{tabular}{lccccc}
\hline \multicolumn{1}{c}{ Source } & DF & SS & MS & F-Value & P-Value \\
\hline Model & 3 & 2552.4 & 850.81 & 8.34 & 0.034 \\
\hline Linear & 2 & 2508.9 & 1254.4 & 12.29 & 0.02 \\
\hline Electric arc current & 1 & 826.89 & 826.89 & 8.1 & 0.047 \\
\hline Melting time & 1 & 1682 & 1682 & 16.48 & 0.015 \\
\hline 2-way interactions & 1 & 43.56 & 43.56 & 0.43 & 0.549 \\
\hline Electric arc current * Melting time & 1 & 43.56 & 43.56 & 0.43 & 0.549 \\
\hline Error & 4 & 408.22 & 102.06 & & \\
\hline Total & 7 & 2960.7 & & & \\
\hline
\end{tabular}

shows ${ }^{13-16}$, for the same alloys, contaminations with oxygen many times higher than the one found in this study.

Those results indicate that using the lowest arc current, lowest melting time, static inert gas atmosphere and absence of Ti-getter, the oxygen contamination in the alloys will be minimized. The use of Ti-getters during the production of BMGs is a well spread method, but the results from this study clearly showed that whether Ti-getter is used or not, the alloys' oxygen concentration will not be significantly altered, probably because the entering inert gas in the chamber was already improved by the $\mathrm{LiH}$ solid state getter in the gas line.

\section{Conclusions}

This study presented a suction casting arc-melting furnace to produce BMGs and statistically studied four factors that might increase the oxygen content during alloy synthesis, finding that for the specific melting conditions applied in this study, the best casting parameters to avoid additional oxygen contamination in production of BMGs alloys were the lowest arc current (200 A), the lowest melting time (11 s), use of a static inert gas (argon) atmosphere previously cleaned with a LiH solid state getter and the absence prior melting of a Ti-getter in the chamber.

\section{Acknowledgements}

The authors would like to thank Boeing Research \& Technology Brazil (BR\&T-Brazil) for the support of this research. The authors would like to thank FAPESP, CNPq, and CAPES for financial support. We thank the writing center, especially Ryan Lambert at the Colorado School of Mines for language assistance.

\section{References}

1. Inoue A. Stabilization of metallic supercooled liquid and bulk amorphous alloys. Acta Mater. 2000;48(1):279-306. http:// dx.doi.org/10.1016/S1359-6454(99)00300-6.

2. Deng L, Zhou B, Yang H, Jiang X, Jiang B, Zhang X. Roles of minor rare-earth elements addition in formation and properties of $\mathrm{Cu}-\mathrm{Zr}-\mathrm{Al}$ bulk metallic glasses. J Alloys Compd. 2015;632:42934. http://dx.doi.org/10.1016/j.jallcom.2015.01.036.

3. Kündig AA, Lepori D, Perry AJ, Rossmann S, Blatter A, Dommann A, et al. Influence of low oxygen contents and alloy refinement on the glass forming ability of $\mathrm{Zr}_{52.5} \mathrm{Cu}_{17.9} \mathrm{Ni}_{14.6} \mathrm{Al}_{10} \mathrm{Ti}_{5}$. Mater Trans. 2002;43:3206-10. http://dx.doi.org/10.2320/ matertrans.43.3206.
4. Suryanarayana C. Encyclopedia of materials: science and technology. New York: Elsevier; 2002. p. 1-10. http://dx.doi. org/10.1016/B0-08-043152-6/01831-3.

5. Inoue A. Bulk amorphous alloys with soft and hard magnetic properties. Mater Sci Eng A. 1997;226-228:357-63. http:// dx.doi.org/10.1016/S0921-5093(97)80049-4.

6. Dong F, Su Y, Luo L, Wang L, Wang S, Guo J, et al. Deoxidation of bulk metallic glasses by hydrogen arc melting. Mater Lett. 2012;83:1-3. http://dx.doi.org/10.1016/j.matlet.2012.05.101.

7. Yan M, Zou J, Shen J. Cooling rate effects on the microstructure and phase formation in $\mathrm{Zr}_{51} \mathrm{Cu}_{20.7} \mathrm{Ni}_{12} \mathrm{Al}_{16.3}$ bulk metallic glass. Sci Technol Adv Mater. 2006;7(8):806-11. http://dx.doi. org/10.1016/j.stam.2006.11.009.

8. Soinila E, Pihlajamäki T, Bossuyt S, Hänninen H. A combined arc-melting and tilt-casting furnace for the manufacture of high-purity bulk metallic glass materials. Rev Sci Instrum. 2011;82(7):073901. http://dx.doi.org/10.1063/1.3606444.

9. Wu FF, Chan KC, Chen SH, Jiang SS, Wang G. ZrCu-based bulk metallic glass composites with large strain-hardening capability. Mater Sci Eng A. 2015;636:502-6. http://dx.doi. org/10.1016/j.msea.2015.04.027.

10. Campos ND No, Pereira FS, Antonio SG, Guo Y, Clarke AJ, Kaufman MJ, et al. Phase formation maps in $\mathrm{Zr}_{48} \mathrm{Cu}_{46.5} \mathrm{Al}_{4} \mathrm{Nb}_{1.5}$ bulk metallic glass composites as a function of cooling rate and oxygen concentration. Mater Charact. 2019;158:109932. http://dx.doi.org/10.1016/j.matchar.2019.109932.

11. Campos ND No, Soares C, Pereira FS, Bergamaschi V, Antonio SG, Kaufman MJ, et al. Glass forming ability and continuouscooling-transformation (CCT) diagrams of Vitreloy 105 as function of cooling rate and oxygen concentration. J NonCryst Solids. 2020;528:119762. http://dx.doi.org/10.1016/j. jnoncrysol.2019.119762.

12. Montgomery DC. Design and analysis of experiments. 8th ed. New York: Wiley; 2012. 730 p.

13. Altounian Z, Batalla E, Strom-Olsen JO, Walter JL. The influence of oxygen and other impurities on the crystallization of $\mathrm{NiZr} 2$ and related metallic glasses. J Appl Phys. 1987;61(1):149-55. http://dx.doi.org/10.1063/1.338847.

14. Kübler A, Eckert J, Gebert A, Schultz L. Influence of oxygen on the viscosity of $\mathrm{Zr}-\mathrm{Al}-\mathrm{Cu}-\mathrm{Ni}$ metallic glasses in the undercooled liquid region. J Appl Phys. 1998;83(6):3438-40. http://dx.doi. org/10.1063/1.367114.

15. Baricco M, Spriano S, Chang I, Petrzhik MI, Battezzati L. "Big cube" phase formation in $\mathrm{Zr}$-based metallic glasses. Mater Sci Eng A. 2001;304-306:305-10. http://dx.doi.org/10.1016/ S0921-5093(00)01438-6.

16. Chen MW, Inoue A, Sakurai T, Ping DH, Hono K. Impurity oxygen redistribution in a nanocrystallized $\mathrm{Zr}_{65} \mathrm{Cr}_{15} \mathrm{Al}_{10} \mathrm{Pd}_{10}$ metallic glass. Appl Phys Lett. 1999;74(6):812-4. http://dx.doi. org/10.1063/1.123376. 